\title{
Research on optimization and assessment of protection shed for the Sun Wu tomb based on microbiological damage control
}

\author{
Yumai Feng ${ }^{1}$, Yonghui $\mathrm{Li}^{1{ }^{1,}, \text { Shuichi Hokoi }}{ }^{1}$, and $\mathrm{Na}$ Dou ${ }^{1}$ \\ ${ }^{1}$ School of Achitecture,Southeast University,Nanjing,Jiangsu,China
}

\begin{abstract}
The Sun Wu tomb in Shangfang Town,Nanjing City is a brick tomb of the Six Dynasties in China,which is very famous for its big scale and complex structure.After being excavated in 2005, microbiological damage occurred on the interior wall of tomb chambers due to the fluctuation of environmental factors, which threatens the historic and culrutal value of this building heritage. Microbiological damage is highly related to the high temperature, high humidity in the tomb chamber and condensation on the wall surface. To solve the problem of microbiological damage in the Sun $\mathrm{Wu}$ tomb, the environment monitoring was carried out and the current protection shed on the Sun $\mathrm{Wu}$ tomb was optimized. the heat and moisture transfer numerical simulation model of the protection shed was built to evaluate the effects of the optimized protection shed for reducing the condensation on the wall surface. The results show that and add of an functional space into the protection scheme can reduce the condensation on the wall surface of the site.In the protection of masonry archaeological sites, design of such functional space can reduce the condensation on the wall surface of the site,so as to control the microbiological damage in the site.
\end{abstract}

\section{Current state of the Sun Wu tomb in Shangfang, Nanjing}

\subsection{Introduction of the Sun Wu tomb in Shangfang, Nanjing}

The Sun $\mathrm{Wu}$ tomb is located in Dongshan street,Shangfang town,Jiangning district, Nanjing city. It is the largest,most complex brick-type tomb of the Dongwu dynasty in China with the most large-scale porcelain unearthed.The identity of the tomb owner is unknown, but the tomb owner is determined to be an emperor or a king $^{[1]}$.

\subsection{Current state and microbial damages in the Sun $\mathrm{Wu}$ tomb}

Due to the influence of high humidity environment, mould growth on the surface of the brick is obvious. There are a lot of mould on the wall of both front and back tomb

* Corresponding author: lyhui2000@qq.com 
chamber.Under the action of microbiological corrosion, the inscriptions on the surface of the brick are obviously blurred or disappeared.

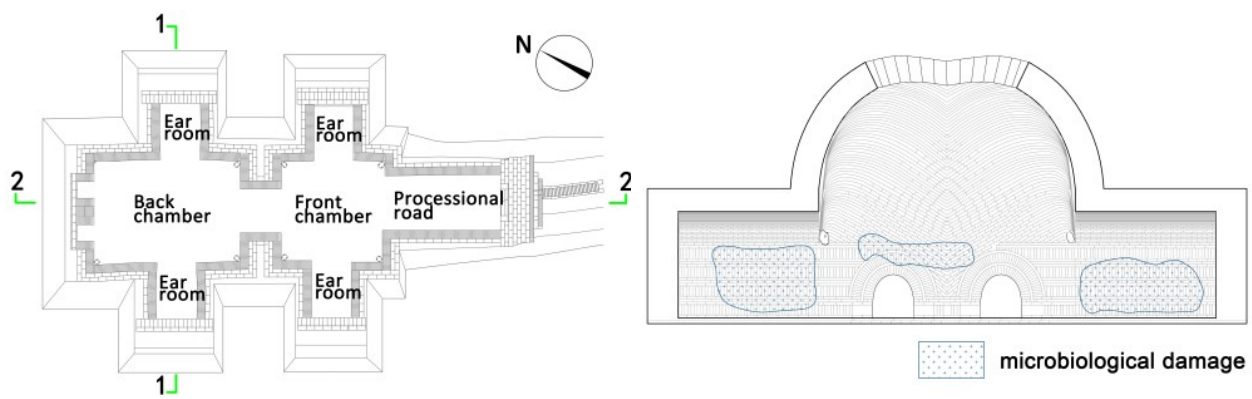

Fig. 1. Plan of the Sun Wu tomb

Fig. 2. Distribution of microbiological damage in Section 1-1

The mould mainly grows on the surface of the lower part of the wall in the tomb, which is near the ground.The phenomenon is related to seepage of ground water and condensation on the wall in the tomb.

\section{Environment monitoring of the Sun Wu tomb}

\subsection{Monitoring scheme}

The outdoor environment monitoring around the Sun $\mathrm{Wu}$ tomb was conducted from July 20th,2015 to June 20th, 2017.Monitoring mainly included three parts: outdoor environmental meteorological parameters, including temperature, humidity, solar radiation, wind speed, wind direction, etc.;indoor environmental parameters of protection shed, including temperature and humidity;temperature and humidity in the tomb chamber.In addition, the height of the underground water level was also monitored.

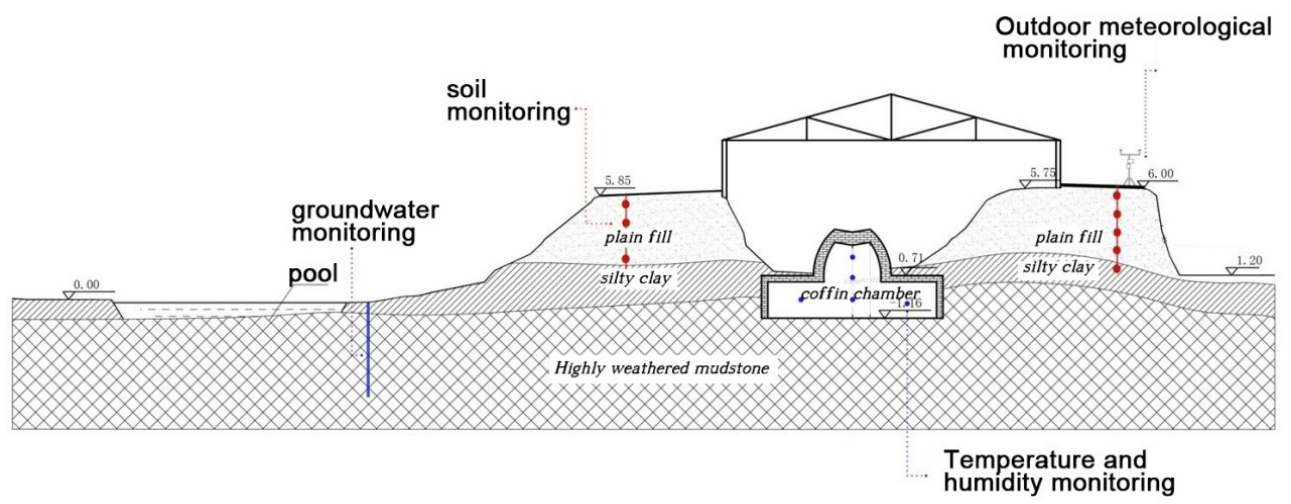

Fig. 3. Monitoring scheme

\subsection{Monitoring data}

As shown in figure 5, the temperature of the outdoor environment surrounding the Sun $\mathrm{Wu}$ tomb fluctuates from $10.162^{\circ} \mathrm{C}$ to $41.619^{\circ} \mathrm{C}$. The average temperature is $16.92^{\circ} \mathrm{C}$ in the two years from July 20th, 2015 to June 20th, 2017.As shown in figure 6, the outdoor total solar radiation outside the Sun $\mathrm{Wu}$ tomb fluctuates between $0 \mathrm{~W} / \mathrm{m}^{2} \sim 1096.9 \mathrm{~W} / \mathrm{m}^{2}$. 


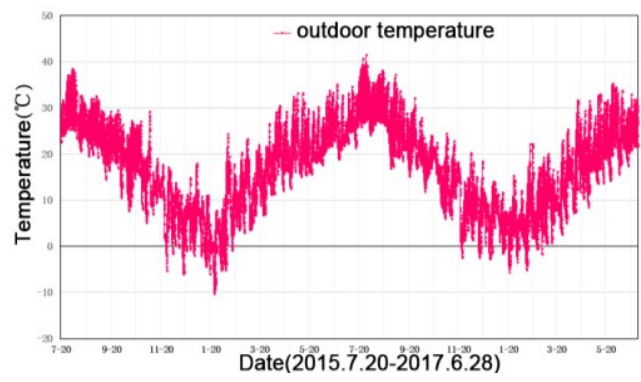

Fig. 4. Outdoor temperature of the Sun $\mathrm{Wu}$ tomb

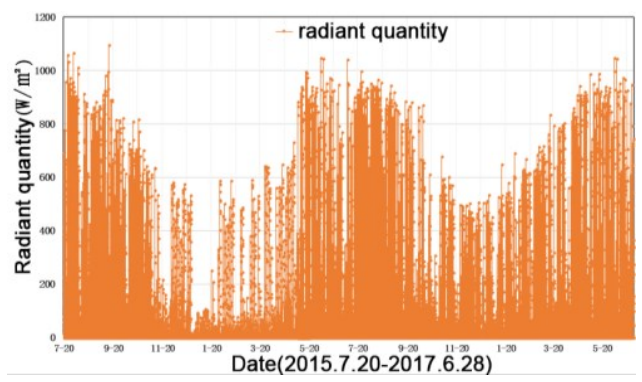

Fig. 5. Total solar radiation outside the shed

\section{Heat and moisture transfer model of the Sun Wu tomb}

\subsection{Basic equation}

Numerical simulation analysis was carried out on the heat and moisture transfer of the Sun $\mathrm{Wu}$ tomb and the surrounding soil under the affection of protection shed. The model was based on the heat and moisture transfer theory driven by the temperature and water chemistry potential, which was proposed by the Japanese scholar Matsumoto ${ }^{[2]}$. The fortran computer program was used for numerical simulation analysis.

Heat balance equation:

$$
c \rho \frac{\partial T}{\partial t}=-\nabla \cdot q_{s}-r \nabla \cdot J_{1 w(s)}
$$

Moisture balance equation:

$$
\begin{gathered}
\rho_{w}\left(\frac{\partial \psi}{\partial \mu}\right) \frac{\partial \mu}{\partial t}=-\nabla \cdot J_{w} \\
\mu=R_{v} T \ln (H) \\
q_{s}=-\lambda \nabla T \\
J_{w}=J_{1 w(s)}+J_{2 w(s)} \\
J_{1 w(s)}=-\lambda_{\mu g}^{\prime}\left(\nabla \mu-n F_{W}\right)-\lambda_{T g}^{\prime} \nabla T \\
J_{2 w(s)}=-\lambda^{\prime}{ }_{\mu l}(\nabla \mu-n G)-\lambda_{T l}^{\prime} \nabla T
\end{gathered}
$$

Here, $c \rho$ is the apparent heat capacity of the material $\left[\mathrm{J} / \mathrm{m}^{3} \mathrm{~K}\right], \mathrm{T}$ is temperature $(\mathrm{K})$, $\lambda$ is thermal conductivity $[\mathrm{W} / \mathrm{mK}], \psi$ is volumetric moisture content $\left(\mathrm{m}^{3} / \mathrm{m}^{3}\right), \mu$ is water chemical potential $(\mathrm{J} / \mathrm{kg}) ; \mathrm{R}_{\mathrm{V}}$ is the universal gas constant for water vapor $\left(\mathrm{Pa} \bullet \mathrm{m}^{3} / \mathrm{kmol} \cdot \mathrm{K}\right)$; $\mathrm{H}$ is relative humidity $(\%), \mathrm{q}_{\mathrm{s}}$ is heat flow density $\left(\mathrm{W} / \mathrm{m}^{2}\right), \mathrm{J}_{1} \mathrm{w}(\mathrm{s})$ and $\mathrm{J}_{2} \mathrm{~W}(\mathrm{~s})$ are gaseous water and liquid water $\left(\mathrm{kg} / \mathrm{m}^{2} \mathrm{~s}\right), \lambda^{\prime} \mu \mathrm{g}$ and $\lambda^{\prime} \mu \mathrm{l}$ are moisture conductivity related to water chemical potential gradient (gas phase and liquid phase) $[\mathrm{kg} / \mathrm{ms}(\mathrm{J} / \mathrm{kg})], \lambda^{\prime} \mathrm{Tg}$ and $\lambda^{\prime} \mathrm{Tl}$ is moisture conductivity related to temperature gradient (gas phase and liquid phase) $[\mathrm{kg} / \mathrm{msK}]$. 
Analytic object and grid division: the cross section of the back chamber of the Sun $\mathrm{Wu}$ tomb in is taken as the analytic object and is divided into hundreds of grids. The mesh is under densification when it covers the tomb chamber and the protection shed.Then an explicit control volume method is adopted for the calculations with a time step of 60 seconds.

The density and thermal conductivity of bricks in Sun $\mathrm{Wu}$ tomb were measured in laboratory, and input into the numerical model.The monitoring data----the outdoor temperature, relative humidity, total solar radiation, collected by the weather station near the protective shed of the Sun Wu tomb from January 1th, 2016 to December 31th,2016, were input into the numerical model as the boundary conditions.

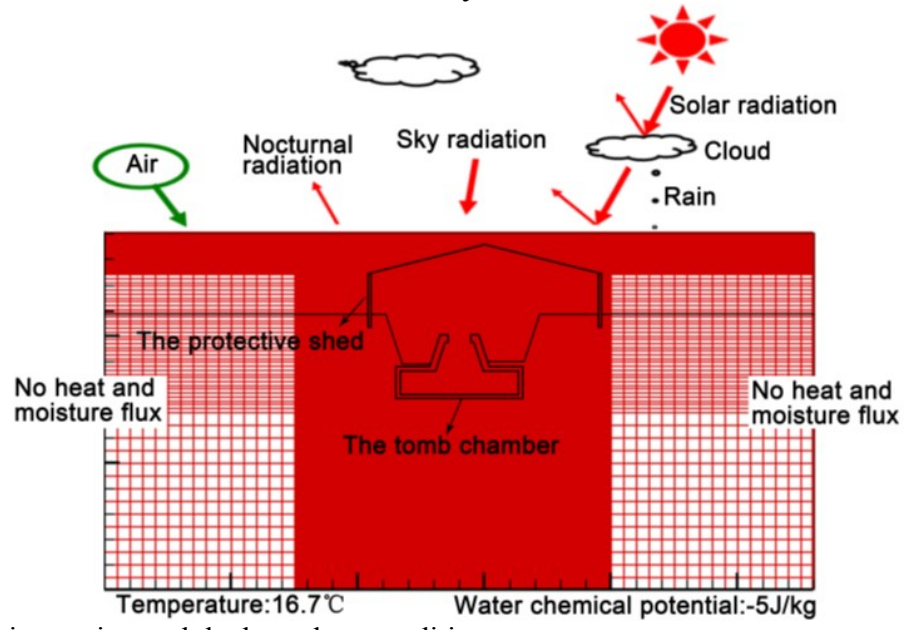

Fig. 6. Calculation region and the boundary conditions

\subsection{Model validation}

The monitoring and simulation values of tomb chamber temperatures in 2016 are both indicated in Fig.7. The monitored temperature in the tomb chamber is $18.7^{\circ} \mathrm{C} \pm 15.0^{\circ} \mathrm{C}$ (amplitude), while the calculated value is $19.5^{\circ} \mathrm{C} \pm 18.9^{\circ} \mathrm{C}$ (amplitude). As for humidity indicated in Fig.8, the monitored $\mathrm{RH}$ in the tomb chamber is $74.5 \% \pm 25 \%$ (amplitude), while the calculated value is $68.7 \% \pm 26.8 \%$ (amplitude). Considering the accuracy of the measuring instruments, the numerical simulation model is considered as reliable in estimating the temperatuer and relative humidity. The following section discusses the hygrothermal behavior in the underground tomb chamber predicted by the model.

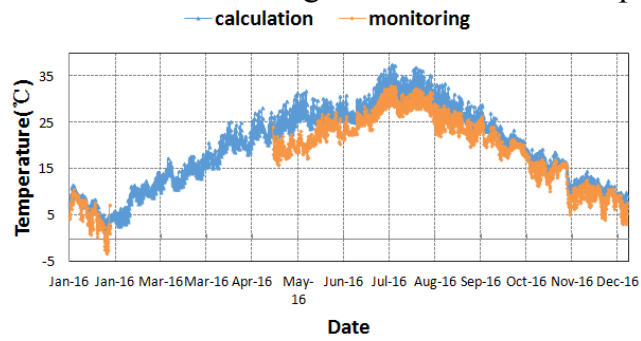

Fig. 7. Temperature in the tomb chamber (monitoring - calculation contrast)

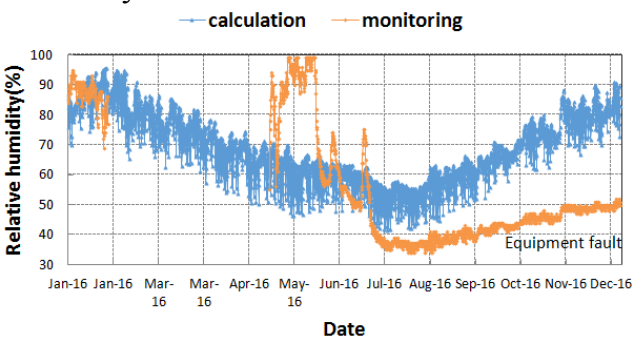

Fig. 8. Humidity in the tomb chamber ( monitoring - calculation contrast) 


\section{Optimization and assesment of the protection shed of the Sun Wu tomb}

\subsection{Optimized design of protection shed}

Microbiological damage is highly related to the high temperature, high humidity in the tomb chamber and condensation on the wall surface ${ }^{[3]}$. The main reason for the occurrence of condensation is that the hot and wet air meets with a cold wall. Thus heating the tomb wall to increase the wall temperature is an effective measure to reduce condensation.

This study considered both the orientation of the protection shed and local solar radiation characteristics to optimize the protection shed.A functional space is added to the protection shed and do heat exchange with the tomb body by means of heat conduction and convection, so as to improve the temperature of the tomb wall. The functional space is enclosed by glass walls, like a sunroom.

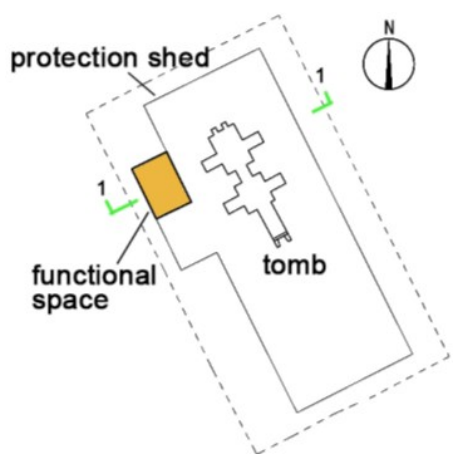

Fig. 9. Plan of optimized design

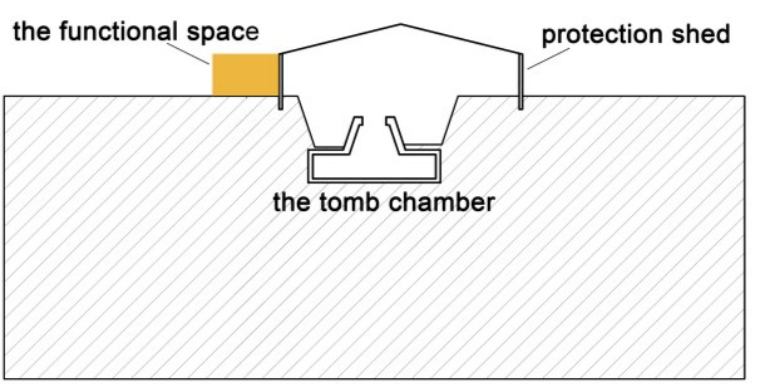

Fig. 10. Calculation region Section 1-1

\subsection{Assesment of the optimization on anti-condensation effects}

In this study, condensation is assumed to occur when the water chemical potential of the wall surface reaches $-50 \mathrm{~J} / \mathrm{kg}$ and there is still water comes in. This definition of condensation is only used to evaluate the risk of severe condensation ${ }^{[4]}$.

$\rightarrow$-after optimized $\rightarrow$ before optimized

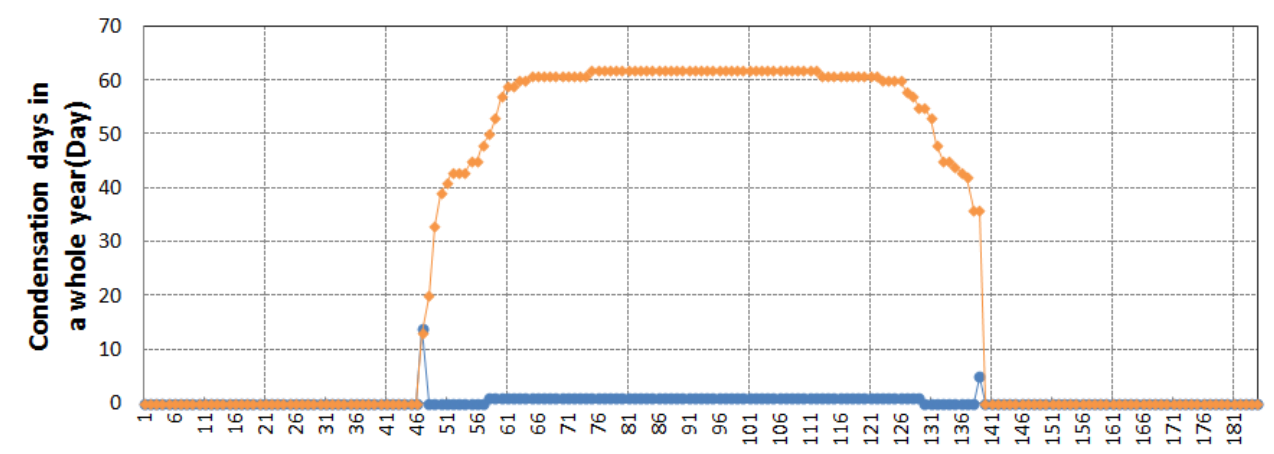

Simulation point on the inner surface of the tomb chamber

Fig. 11. Condensation days on each simulation point -- contrast of before and after optimized protection shed 
According to the numerical simulation results, Figure11 shows the contrast of the original and the optimized protection shed in number of days when condensation occurs on each simulation point around the back tomb chamber section in the whole year of 2016 . It can be seen that before the protection shed is optimized,condensation is easily occurred on the both sides and the bottom of the tomb chamber.After optimization, condensation is almostly occurred on the bottom for only less than 10 days in a year.

According to the numerical simulation results of the original protection shed and the optimized protection shed, the contrast of condensation rate on the wall surface of the back tomb chamber section in each month of 2016 is shown in Figure12:

$\rightarrow$ after optimized $\rightarrow$ before optimized

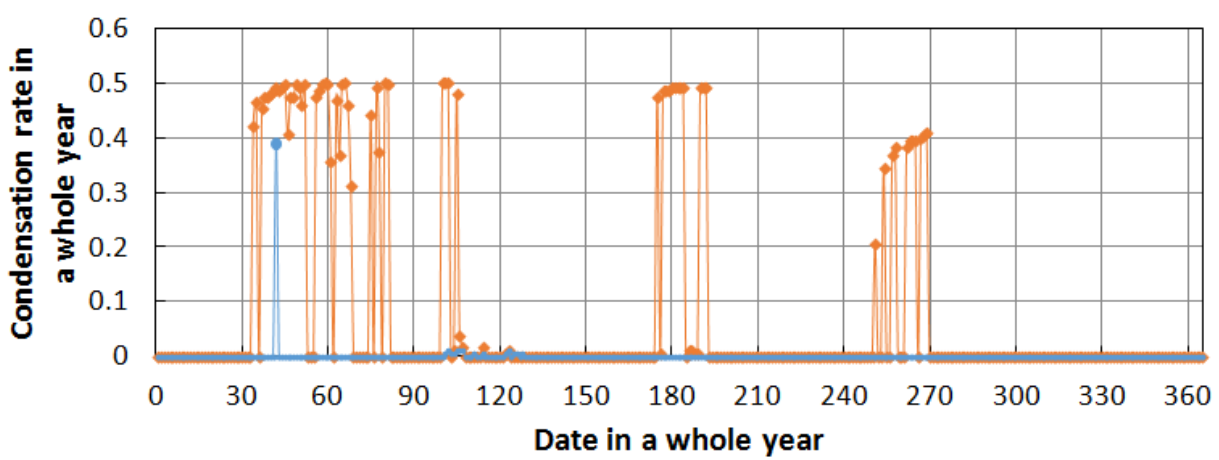

Fig. 12. Contrast of condensation rate in each month of 2016 -- contrast of original and optimized protection shed

Figure12 shows that before the protection shed is optimized,condensation is easily occurred in spring,summer and autumn.After optimization, condensation occurred nearly only in the early spring.

\section{Conclusion}

The temperature variation and distribution in the architectural heritage can be well simulated by heat and moisture transfer numerical simulation model. In protection of masonry building heritages, design of such functional space like sun rooms can reduce the condensation on the wall surface of the building heritage, so as to control the deterioration of microbiologicals in the site and achieve the purpose of architectural heritage conservation.

Acknowledgements: I would like to express my gratitude to my supervisor A/Prof. Yonghui Li and Prof.Shuichi Hokoy for the comprehensive guidance and to my senior sisters Na Dou and Yan Ma for their guidance on my programming. I could not have completed this paper without their help.

\section{References}

[1] Z. Wang, T. Ma, J. Gong, W. Zhou, C. Xu, R. Zhou, S. Cui, B. Dong, Q. Wang, Y. Li, Cul. Rel. J. 12, 34-35(2008)

[2] M. Matsumoto. D. Kyoto University(1978)

[3] S. Johansson, W. Lars, K. Sandin. Build Environ. J. 45, 1153-1160 ( 2010)

[4] Y. Li, D. Ogura, S. Hokoi, J. Wang, T. Ishizaki, J. ASIAN ARCHIT. BUILD. ENG. J. 13, 499-506(2014) 